\title{
Experimental Study of the Water-Sediment Two-Phase Seepage Characteristics in Rock Fractures and the Influencing Factors
}

\author{
Kui Di, ${ }^{1}$ Ming Li $\mathbb{D}^{1},{ }^{1}$ Xianbiao Mao, ${ }^{1}$ Zhanqing Chen, ${ }^{1}$ Lianying Zhang, ${ }^{2}$ and Yu Han ${ }^{1}$ \\ ${ }^{1}$ State Key Laboratory for Geomechanics and Deep Underground Engineering, China University of Mining and Technology, Xuzhou, \\ 221116 Jiangsu, China \\ ${ }^{2}$ School of Civil Engineering, Xuzhou University of Technology, Xuzhou, 221018 Jiangsu, China
}

Correspondence should be addressed to Ming Li; mingl@cumt.edu.cn

Received 12 August 2021; Accepted 22 September 2021; Published 25 November 2021

Academic Editor: Andri Stefansson

Copyright (c) 2021 Kui Di et al. This is an open access article distributed under the Creative Commons Attribution License, which permits unrestricted use, distribution, and reproduction in any medium, provided the original work is properly cited.

\begin{abstract}
The water-sediment two-phase seepage in coarse fractures is one of the major factors to trigger mine water inrush disasters. Based on seepage mechanics theory, a mechanical model of the water-sediment two-phase seepage in coarse fractures was established. An experimental system was also developed to study the seepage characteristics under various conditions. The relationships between the absolute value of the pressure gradient and the seepage velocity were analyzed during the test process. The nonlinear characteristics of the seepage test were revealed. In addition, variation laws of the absolute value of the pressure gradient with the sand volume fraction and the sand particle size were illustrated, which were related to the loss of pressure during the particle movement. The impacts of the sand volume fraction and the sand particle size on the equivalent fluidity and $\beta$-factor of non-Darcy flow were discussed and analyzed. It was determined that the local turbulence was the main reason for the change of nonlinear variation characteristics of seepage parameters.
\end{abstract}

\section{Introduction}

Water inrush is one of the major disasters affecting coal mine safety production. It causes the direct cost of tens of billions of yuan every year in China. Therefore, it is of great significance to find clear water inrush disaster mechanisms and effectively control the disasters for the construction of green mines in China $[1,2]$. Water-sediment two-phase flow in course fractures is the precursor of mine water inrush disasters. It is the key to study seepage characteristics of the water-sediment mixture to reveal the mine water inrush mechanism.

The formation of fissure channels and the seepage of water-sediment mixture are two core factors of mine water inrush disasters. The fissure channels are caused by the surrounding rock deformation during the roadway driving and the mining of the working face [3-5]. The surface of the fracture is usually coarse. The water-sediment mixture mainly exists in old roofs or water-rich areas $[6,7]$. The content of the water-sediment mixture is mainly water, and the content of sand is less in Eastern China, while thick sand layers usually exist above coal seams in Northwest China. A complete channel penetrating fractures will form after the overburden failure [8]. Then, the overlying thick land layers will flow to fractures along with the water and thus trigger water and sand inrush disasters. Many scholars used numerical calculation methods to reveal the complete process of water-sediment two-phase flow, and they adopted the software, such as ANSYS, FLAC, PFC, and COMSOL, to study the seepage fields and stress fields [9-12]. However, the numerical calculation results have limited guidance value for actual engineering, due to inaccurate mechanical parameters and simplified models. Therefore, scholars are trying to find more scientific methods to study mechanical problems of water-sediment two-phase seepage.

Limited by the testing equipment, the water-sediment two-phase seepage experiments took water and prefabricated parallel fractures as research objects [13]. With the development of test equipment and the signal acquisition system, water-sediment two-phase seepage experiments in coarse fractures were carried out and a series of research results were achieved [14-16]. Based on a large number of 


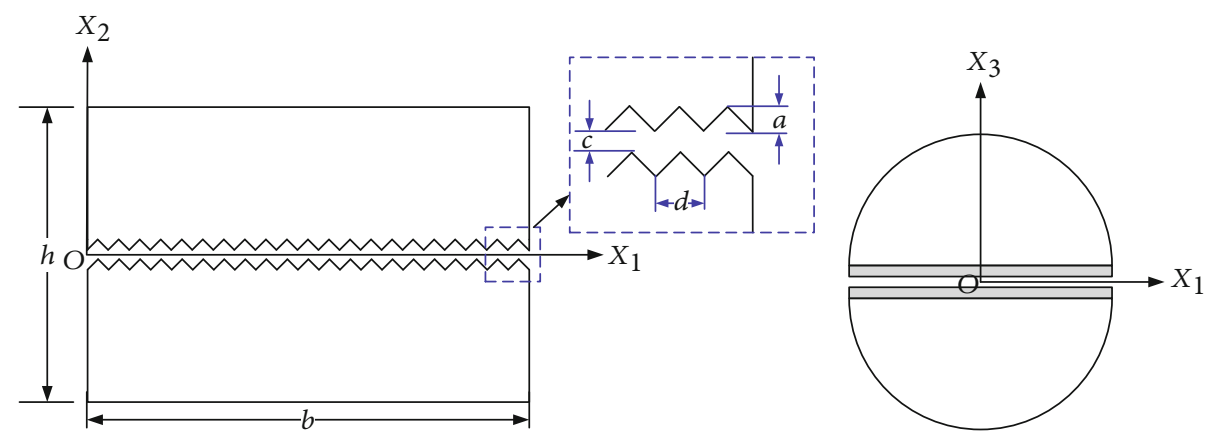

Figure 1: Structure and size of the fracture specimen.

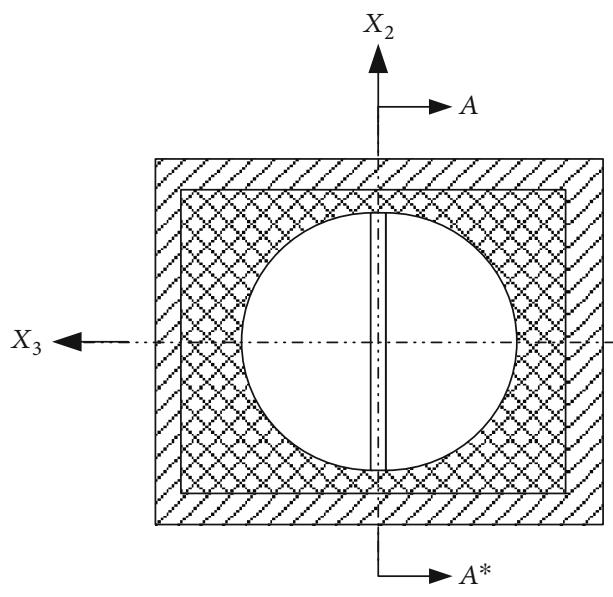

(a) Installation methods of specimens

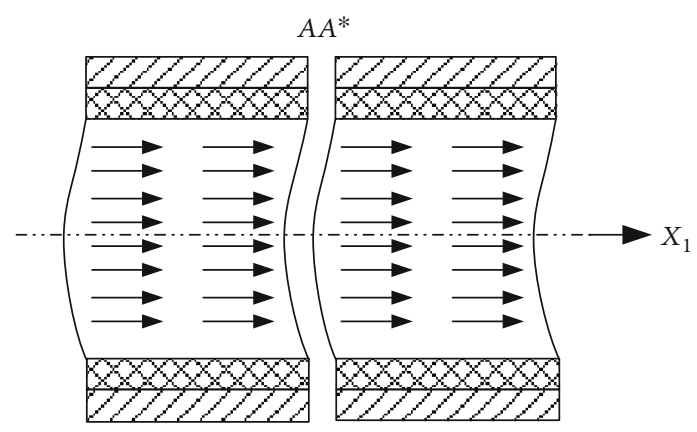

(b) Seepage velocity distribution

Figure 2: Water-sediment seepage principles inside the fissures.

studies on the water-sediment seepage process in coarse fractures, scholars mainly study the factors affecting the seepage characteristics, including fracture roughness, fracture aperture, sediment concentration, and sand particle size [17-21]. However, the current studies on fracture seepage mainly focus on a single-fluid seepage field and rarely involve the liquid-solid two-phase flow in fractures [22, 23]. When the particle concentration is relatively low, the particle cannot be treated as the quasi-fluid and the interphase forces cannot be ignored. At the point, watersediment transport can be treated neither as two-fluid seepage nor as single-fluid seepage. The research on particle phase and continuous phase flow in fractures is rare.

At present, there is rare research involving the liquidsolid two-phase flow in fractures. In the paper, a mechanical model of water-sediment two-phase seepage in coarse fractures was established based on the seepage mechanics theory. A testing system was built to simulate watersediment two-phase seepage in coarse fractures. Then, the mechanical test was carried out by using prefabricated coarse fracture specimens. The water-sediment two-phase seepage characteristics and the influencing factors were studied systematically. The test results are aimed at revealing the water and sediment inrush mechanism and providing references for water-sediment inrush disaster prediction and control.

\section{Experimental Principles and Introduction}

2.1. Preparation of Coarse Fracture Specimens. Natural rock specimens are generally used to get fissure surfaces by fracture splitting in fluid flow experiment in fractures. The obtained fractures are relatively close to the actual fractures but cannot be used to describe geometrical characteristics and construct the numerical model. Meanwhile, the composition of natural rock is complex and may easily cause a water-soluble phenomenon to occur, which will affect the experimental results. On this basis, Ni-Cr alloys (06Cr19Ni10 GB/T 20878-2007) were used to make coarse fracture specimens in this experiment. Figure 1 shows the sizes of fracture specimens. The height $(b$ ) is $100 \mathrm{~mm}$, and the diameter $(h)$ is $70 \mathrm{~mm}+2 a+c$. The projections of the fissure surfaces on the longitudinal section are continuous and uniform distributed isosceles triangles. The height of the triangle $(a)$ is $1 \mathrm{~m}$. The distance between two fissure surfaces $(d)$ is $2 \mathrm{~mm}$. The fissure aperture $(c)$ is $0.8 \mathrm{~mm}$. The fissures are anastomosed between two fissure surfaces. Water and quartz sand were used as the liquid phase and solid phase, respectively, for the experiment.

2.2. Experimental Principles and the Test System Establishment. Water and sediment belong to solid-liquid two-phase mixtures. The flow of water and sediment in fractures is complex turbulent flow. In this paper, a generalized 


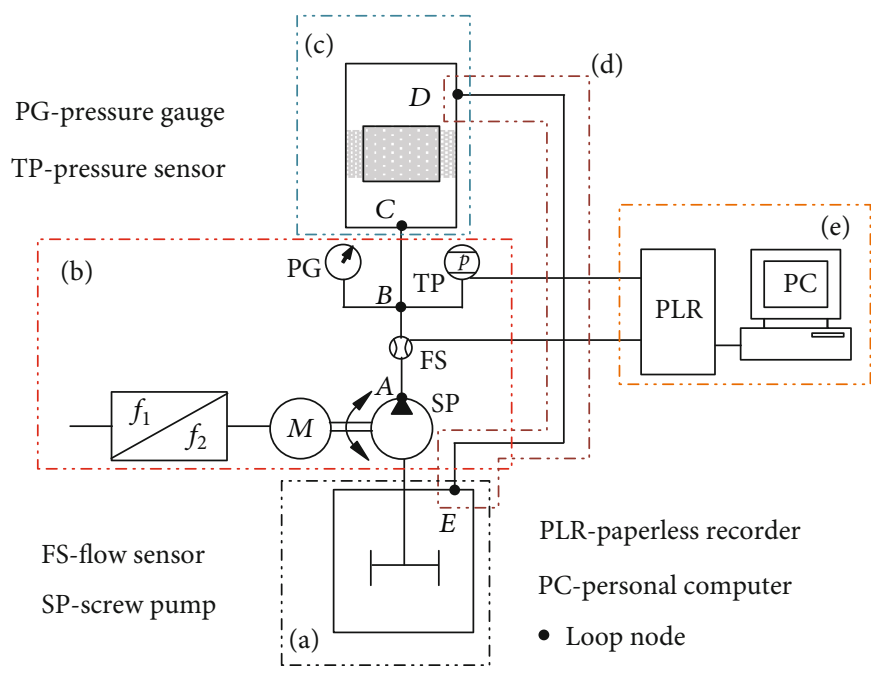

Figure 3: The water-sediment seepage testing system in fissures (a: the stirring system; $b$, d: the water-sediment transport system; $c$ : permeameter; and e: control panel).
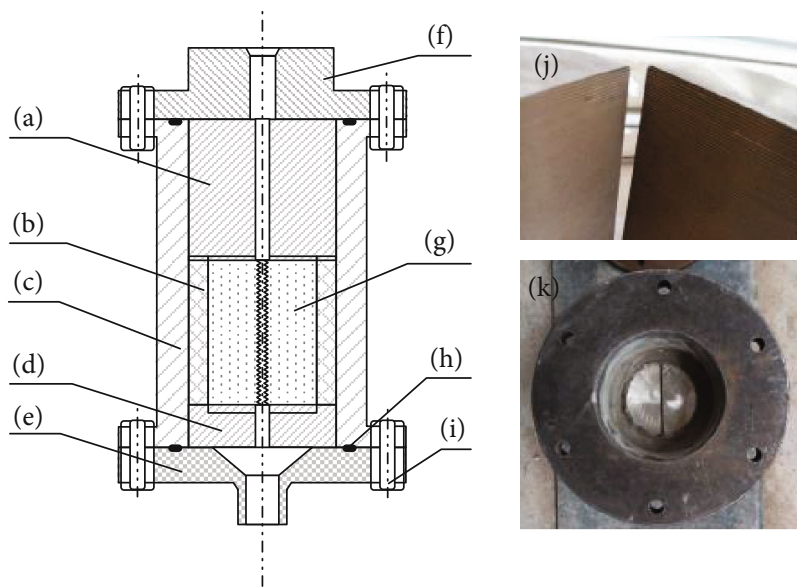

FIGURE 4: Seepage system and specimen installation method (a: upper water-conducting transition plate; b: high water material; $c$ : cylinder tube; d: lower water-conducting transition plate; e: conical base; f: capping; g: fissure specimen; h: O-shaped rubber seal ring; i: bolt; $\mathrm{j}$ : coarse fissure surface; $\mathrm{k}$ : the inner of the seepage system).

flow-seepage was used to simplify actual flow of water and sediment. Taking the direction parallel to crack length as the $X_{1}$ axis and the direction of crack aperture as the $X_{2}$ axis, the coordinate system $O X_{1} X_{2} X_{3}$ was established according to right-hand grip rule, as shown in Figure 1.

In actual flow, the distributions of water flow rate $\vec{v}$, sand flow rate $\overrightarrow{v^{\mathrm{p}}}$, hydraulic pressure $p$, and sediment concentration (fractional volume $\Phi$ ) are uniform. This is because fracture surfaces have unilateral constraints to water and sediment.

In seepage mechanics, the normal distributions of flow velocities among fractures are usually not considered along the fissure surfaces, and the seepage velocity (the average seepage velocity along the fracture width direction) is used to replace the permeability velocity. The water phase seepage velocity was marked as $\vec{V}$, the sand phase seepage velocity was marked as $\overrightarrow{V^{\mathrm{p}}}$, and the distance between two fissure surfaces was marked as $c$; then, the following equations could be obtained.

$$
\begin{array}{r}
\vec{V}=\frac{1}{c} \int_{0}^{c} \vec{v} \mathrm{~d} x_{2}, \\
\overrightarrow{V^{\mathrm{P}}}=\frac{1}{c} \int_{0}^{c} \overrightarrow{v^{\mathrm{P}}} \mathrm{d} x_{2},
\end{array}
$$

where $x_{2}$ is the local coordinate. The transformation relation between $x_{2}$ and $X_{2}$ is given as follows:

$$
x_{2}=X_{2}-X_{2}^{*}
$$

where $X_{2}^{*}$ is the coordinate of $X_{2}$, the point of intersection between the lower fissure surface and cross section.

As shown in Figures 1 and 2, the seepage velocities $\vec{V}$ and $\overrightarrow{V^{\mathrm{P}}}$ were one dimension less than the actual flow velocities $\vec{v}$ and $\overrightarrow{v^{\mathrm{P}}}$. To facilitate the analysis, the physical quantity was assumed to be constant along the direction of $X_{3}$. Thus, the actual flow velocities $\vec{v}$ and $\overrightarrow{v^{\mathrm{P}}}$ were two-dimensional, while the seepage velocities $\vec{V}$ and $\overrightarrow{V^{\mathrm{p}}}$ were one-dimensional, that is,

$$
\begin{aligned}
\vec{v} & =\overrightarrow{f_{\mathrm{v}}}\left(X_{1}, X_{2} ; t\right), \\
\overrightarrow{v^{\mathrm{p}}} & =\overrightarrow{f_{\mathrm{v}}^{\mathrm{p}}}\left(X_{1}, X_{2} ; t\right), \\
\vec{V} & =\overrightarrow{F_{\mathrm{v}}}\left(X_{1} ; t\right), \\
\overrightarrow{V^{\mathrm{P}}} & =\overrightarrow{F_{\mathrm{v}}^{\mathrm{p}}}\left(X_{1} ; t\right) .
\end{aligned}
$$

In seepage experiments, the distributions of flow velocities along direction $X_{2}$ were unavailable, so flow velocities in fissures 


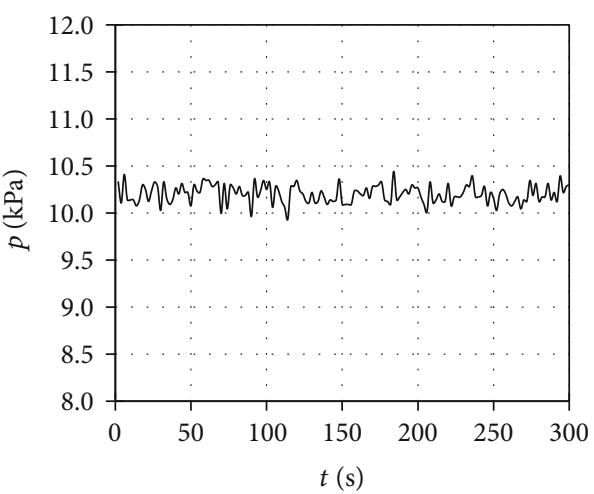

(a) Pressure-time

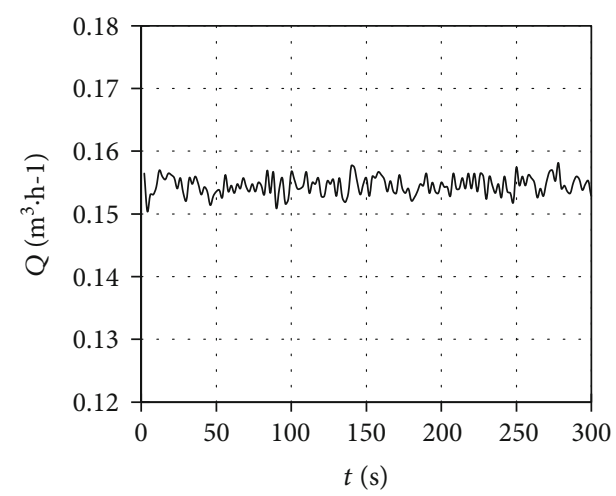

(b) Flow-time

Figure 5: Pressure-time curve and flow-time curve ( $n=200 \mathrm{r} / \mathrm{min})$.

were measured. The experimental phenomena and watersediment flow laws were explained and analyzed by viewpoints and theory of seepage mechanics.

During the seepage of water and sediment in two parallel fissure surfaces, the water was the Newtonian fluid, while the sediment was the non-Newtonian fluid. The fissure surfaces are curved surfaces generated by polyline translation.

$\vec{e}_{i}(i=1,2,3)$ was the base vector of the coordinate system $O X_{1} X_{2} X_{3}$; then, the seepage velocity was $\vec{V}=V \vec{e}_{1}$ and $\overrightarrow{V^{\mathrm{P}}}=V^{\mathrm{p}} \vec{e}_{1}$. The sum of the water flow and sediment flow in fissures could be obtained by the following equation:

$$
Q=V \Phi^{\mathrm{w}} h D+V^{\mathrm{p}} \Phi h D,
$$

where $\Phi^{\mathrm{w}}$ is the volume fraction of water and $\Phi$ is the volume fraction of sediment. Due to

$$
\boldsymbol{\Phi}^{\mathrm{W}}+\boldsymbol{\Phi}=1
$$

equation (8) could be transformed into

$$
Q=\left[V\left(1-\Phi^{\mathrm{w}}\right)+V^{\mathrm{p}} \Phi\right] h D .
$$

Therefore, the seepage velocity of the water-sediment mixture could be obtained by

$$
V=\frac{Q}{h D}=V\left(1-\Phi^{\mathrm{W}}\right)+V^{\mathrm{p}} \Phi .
$$

To realize accurate measurement of flow in fissures, the following boundary conditions should be met for watersediment flow.

$$
\begin{gathered}
\left.V_{2}\right|_{X_{3}= \pm D / 2}=0,\left.V_{3}\right|_{X_{3}= \pm D / 2}=0, \\
\left.V_{2}^{\mathrm{p}}\right|_{X_{3}= \pm D / 2}=0,\left.V_{3}^{\mathrm{p}}\right|_{X_{3}= \pm D / 2}=0 .
\end{gathered}
$$

In the experiment, $X_{3}= \pm D / 2$ was set as the closed boundary without mass transfer.

To realize the boundary conditions in equations (12) and (13), high water seal materials were used around two specimens with fissure surfaces. A rigid frame was arranged outside the high water materials, as shown in Figure 2(a). The seepage velocity of fluids was parallel to the $X_{1}$ axis, as shown in Figure 2(b).

According to principles in Figure 2, a water-sediment seepage test system in fissures was designed, as shown in Figure 3. The system consists of a stirring system ( $a$ in Figure 3), a water-sediment transport system (b and $d$ in Figure 3), a self-developed permeameter (c in Figure 3), and a control panel (e in Figure 3). Figure 4 shows the installation methods of the permeameter and specimens. Manual control was used for the relative positions between fissure surfaces. Firstly, the specimen was sealed in the cylinder tube. A $0.8 \mathrm{~mm}$ copper wire was placed on the fissure surface along both sides of the specimen. High water materials were filled between the specimen and cylinder tube.

2.3. Calculation Methods of Characterization Parameters. The water-sediment mixture flow in coarse fissures belongs to typical non-Darcy flow. In the experiment, the equivalent fluidity $I_{\mathrm{e}}$ and the $\beta$-factor of non-Darcy flow were chosen as characterization parameters.

The inner diameter of pipe-segment $\mathrm{ABC}$ was $d_{\text {tube }}$, and the average flow velocity could be obtained by

$$
V_{\text {tube }}=\frac{4 Q}{\pi d_{\text {tube }}^{2}} .
$$

The seepage velocity in fissures could be calculated by

$$
V=\frac{Q}{B D} .
$$

On the precondition that linear loss and local loss were neglected, the Bernoulli equation was given as follows:

$$
\frac{p_{\text {tube }}}{\rho^{*} g}+\frac{V_{B}^{2}}{2 g}=\frac{p_{1}}{\rho^{*} g}+\frac{V^{2}}{2 g}+\Delta H
$$

where $\rho^{*}, \rho$, and $\rho^{\mathrm{p}}$ are densities of water-sediment mixture, water, and sand, respectively, and $\rho^{*}=\rho^{\mathrm{P}} \Phi+\rho(1-\Phi)$. 


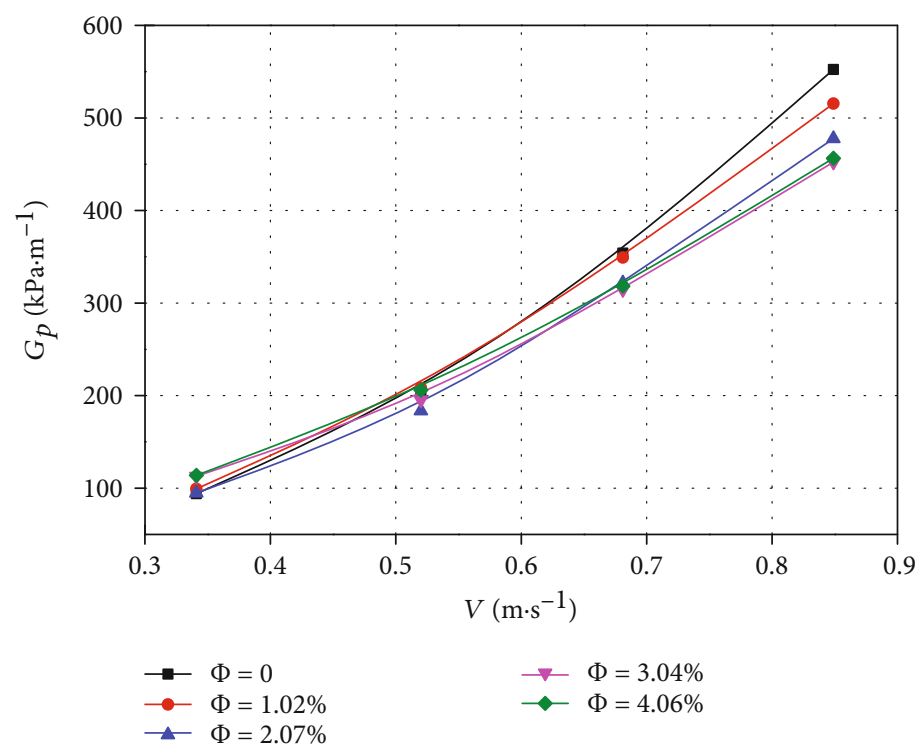

(a) $D_{\mathrm{p}}=0.02-0.06 \mathrm{~mm}$

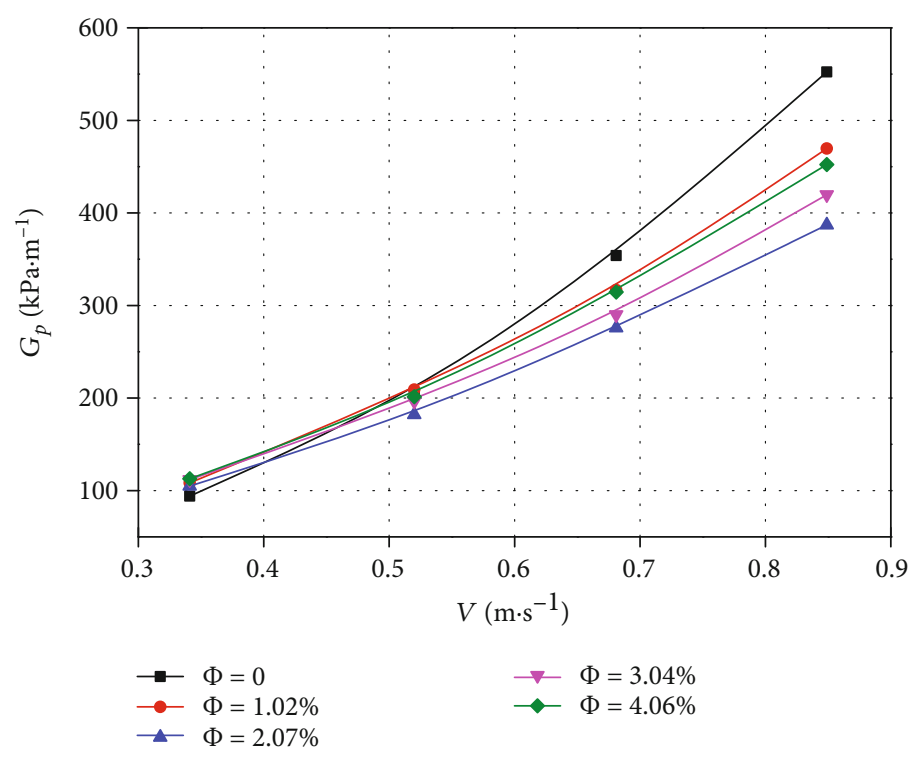

(b) $D_{\mathrm{p}}=0.06-0.10 \mathrm{~mm}$

Figure 6: Continued. 


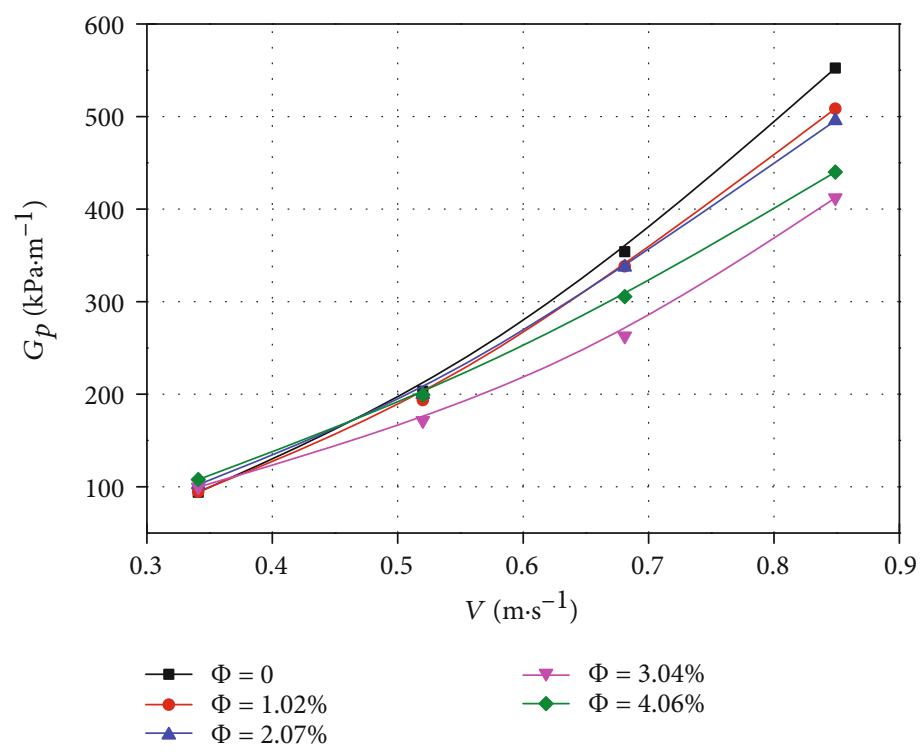

(c) $D_{\mathrm{p}}=0.10-0.14 \mathrm{~mm}$

Figure 6: $G_{\mathrm{p}}$ Abs- $V$ curves.

$g$ is the acceleration of gravity. $p_{1}$ is the pressure at fissure entrance. $\Delta H$ is the height difference between point $B$ and the middle of the fissure surface $(\Delta H$ was about $1.1 \mathrm{~m}$ in this system). Equation (16) could be used to get the pressure $p_{1}$ at the entrance of the fracture.

The outlet of the fracture was open, so the pressure $p_{2}$ was approximately equal to zero. Then, the average pressure gradient of water-sediment mixture along $X_{1}$ was given:

$$
\left.\frac{\partial p}{\partial x}\right|_{\text {average }}=-\frac{p_{1}}{L}
$$

That is, the absolute value of the pressure gradient $G_{\mathrm{p}}$ could be calculated by

$$
G_{\mathrm{p}}=\frac{p_{1}}{L}
$$

The water-sediment mixtures were treated as power law fluids. The power exponent was marked as $n$. Then, in steady-state flow, the equivalent fluidity $I_{\mathrm{e}}, \beta$-factor of non-Darcy, seepage velocity $V$, and absolute value of pressure gradient $G_{\mathrm{p}}$ could meet the following relation:

$$
\frac{1}{I_{\mathrm{e}}} V^{n}+\rho^{*} \beta V^{2}=-\frac{p_{2}-p_{1}}{L} .
$$

Considering $p_{2}=0$, equation (19) could be simplified as

$$
\frac{1}{I_{\mathrm{e}}} V^{n}+\rho^{*} \beta V^{2}=\frac{p_{1}}{L}
$$

According to equation (18), equation (21) could be obtained.

$$
\frac{1}{I_{\mathrm{e}}} V^{n}+\rho^{*} \beta V^{2}=G_{\mathrm{p}} .
$$

By introducing the symbol $\lambda_{1}$ and $\lambda_{2}$, equation (22) could be obtained.

$$
\left\{\begin{array}{l}
\lambda_{1}=\frac{1}{I_{\mathrm{e}}}, \\
\lambda_{2}=\rho^{*} \beta .
\end{array}\right.
$$

Then, equation (21) could be transformed into

$$
\lambda_{1} V^{n}+\lambda_{2} V^{2}=G_{\mathrm{p}}
$$

In this experiment, four groups of screw pump rotation speeds were set. The flow and the pressure at the entrance were $Q_{i}$ and $p_{1}^{i}$, respectively. The corresponding seepage velocity $V_{i}$ and the absolute value of the pressure gradient were $G_{\mathrm{p}}^{i}, i=1,2,3,4$.

The functional was constructed as follows:

$$
\Pi=\sum_{i=1}^{4}\left(\lambda_{1} V_{i}^{n}+\lambda_{2} V_{i}^{2}-G_{\mathrm{p}}^{i}\right)^{2}=0
$$

To take the minimum value of $\Pi$, equation (25) could be obtained.

$$
\left\{\begin{array}{l}
\left(\sum_{i=1}^{4} V_{i}^{2 n}\right) \lambda_{1}+\left(\sum_{i=1}^{4} V_{i}^{2+n}\right) \lambda_{2}=\left(\sum_{i=1}^{4} V_{i}^{n} G_{\mathrm{p}}^{i}\right), \\
\left(\sum_{i=1}^{4} V_{i}^{2+n}\right) \lambda_{1}+\left(\sum_{i=1}^{4} V_{i}^{4}\right) \lambda_{2}=\left(\sum_{i=1}^{4} V_{i}^{2} G_{\mathrm{p}}^{i}\right) .
\end{array}\right.
$$



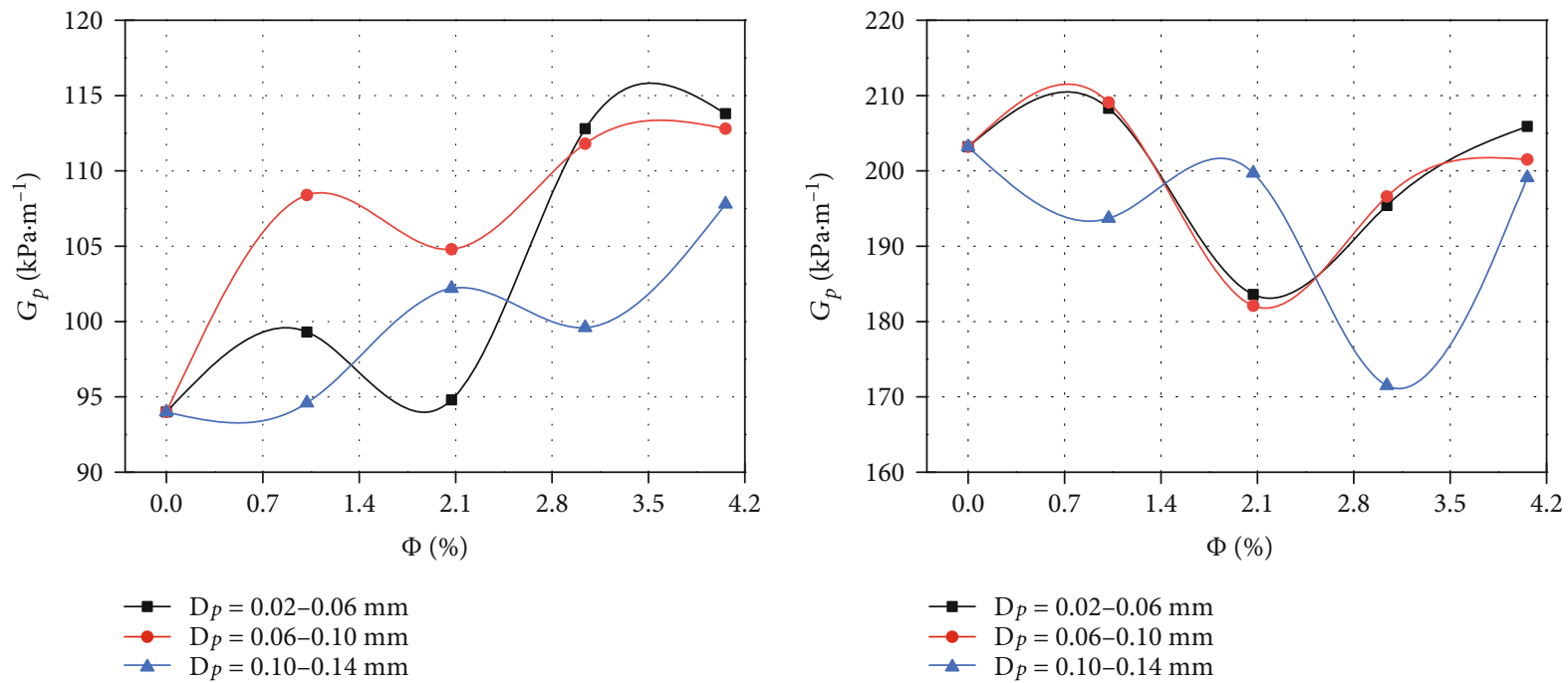

(a) $n=200 \mathrm{r} / \mathrm{min}$

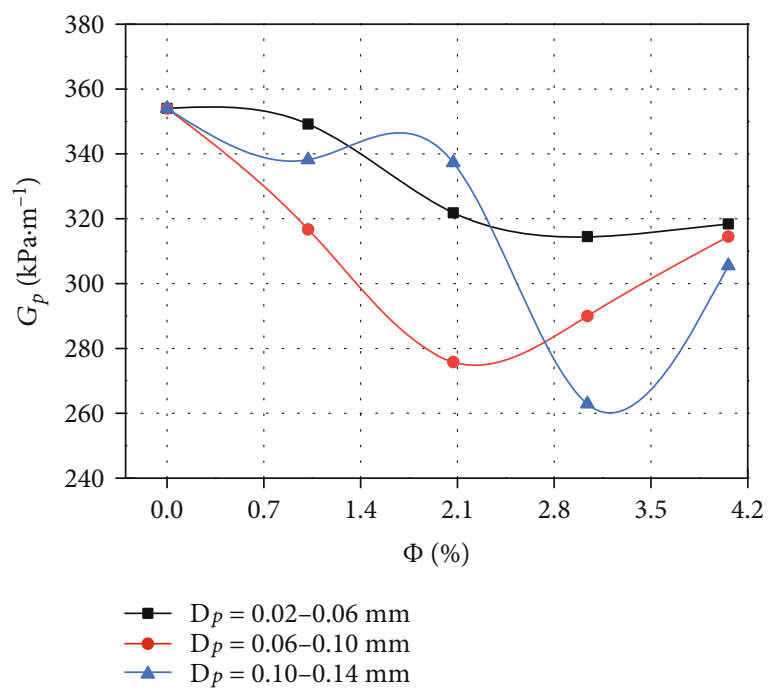

(c) $n=600 \mathrm{r} / \mathrm{min}$

(b) $n=400 \mathrm{r} / \mathrm{min}$

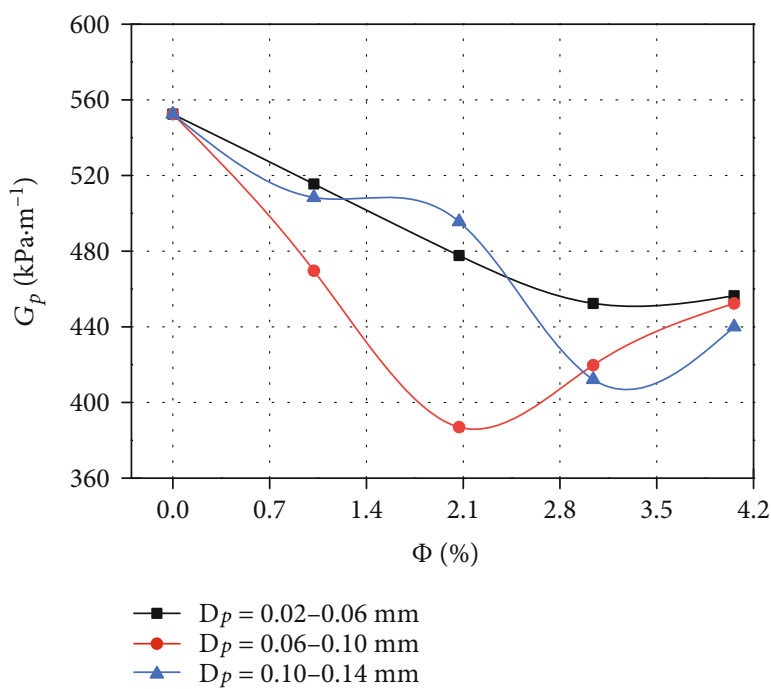

(d) $n=800 \mathrm{r} / \mathrm{min}$

FIgURE 7: $G_{\mathrm{p}}-\Phi$ curves.

The solution of equation (25) was calculated as follows:

$$
\left\{\begin{array}{l}
\lambda_{1}=\frac{\left(\sum_{i=1}^{4} V_{i}^{n} G_{\mathrm{p}}^{i}\right)\left(\sum_{i=1}^{4} V_{i}^{4}\right)-\left(\sum_{i=1}^{4} V_{i}^{2+n}\right)\left(\sum_{i=1}^{4} V_{i}^{2} G_{\mathrm{p}}^{i}\right)}{\left(\sum_{i=1}^{4} V_{i}^{2 n}\right)\left(\sum_{i=1}^{4} V_{i}^{4}\right)-\left(\sum_{i=1}^{4} V_{i}^{2+n}\right)\left(\sum_{i=1}^{4} V_{i}^{2+n}\right)} \\
\lambda_{2}=\frac{\left(\sum_{i=1}^{4} V_{i}^{2 n}\right)\left(\sum_{i=1}^{4} V_{i}^{2} G_{\mathrm{p}}^{i}\right)-\left(\sum_{i=1}^{4} V_{i}^{n} G_{\mathrm{p}}^{i}\right)\left(\sum_{i=1}^{4} V_{i}^{2+n}\right)}{\left(\sum_{i=1}^{4} V_{i}^{2 n}\right)\left(\sum_{i=1}^{4} V_{i}^{4}\right)-\left(\sum_{i=1}^{4} V_{i}^{2+n}\right)\left(\sum_{i=1}^{4} V_{i}^{2+n}\right)} .
\end{array}\right.
$$

By using equation (22), the equivalent fluidity $I_{\mathrm{e}}$ and $\beta$ -factor of non-Darcy flow could be obtained as follows:

$$
I_{\mathrm{e}}=\frac{1}{\lambda_{1}},
$$

$$
\beta=\frac{\lambda_{2}}{\rho^{*}} .
$$

2.4. The Testing Scheme and Methods. In this experiment, the sediment particle size $D_{\mathrm{p}}$ and the sediment volume fraction (concentration) $\Phi$ were selected as variables to study watersediment two-phase seepage characteristics in coarse fractures. There were three groups of $D_{\mathrm{p}}$, that is, $0.02-0.06 \mathrm{~mm}, 0.06$ $0.10 \mathrm{~mm}$, and $0.10-0.14 \mathrm{~mm}$. $\Phi$ values were divided into five groups, that is, $0 \%, 1.02 \%, 2.07 \%, 3.04 \%$, and $4.06 \%$.

The whole process is as follows:

(i) The first step is to pour water into the stirring pool with the inner diameter of $D_{\text {pool }}$. The depth of water was $H_{\mathrm{w}}$. Then, the volume of water was $B_{\mathrm{w}}=(\pi / 4)$ $D_{\text {pool }}^{2} H_{\mathrm{w}}$. The sediment volume required for the test could be converted according to $\Phi$, that is, 


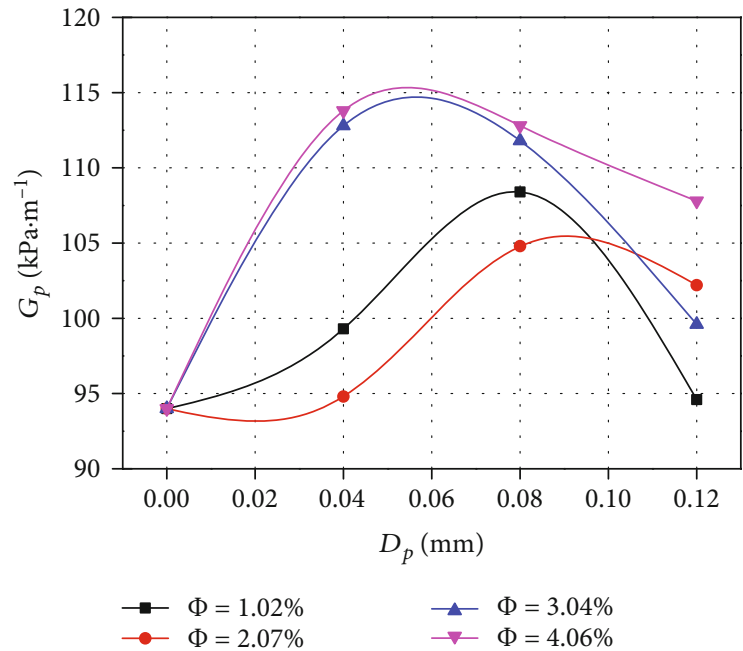

(a) $n=200 \mathrm{r} / \mathrm{min}$

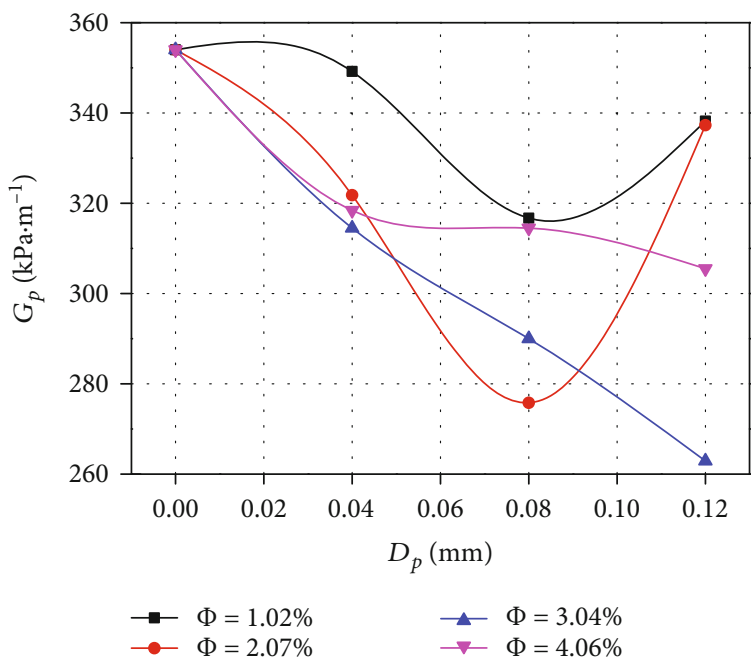

(c) $n=600 \mathrm{r} / \mathrm{min}$

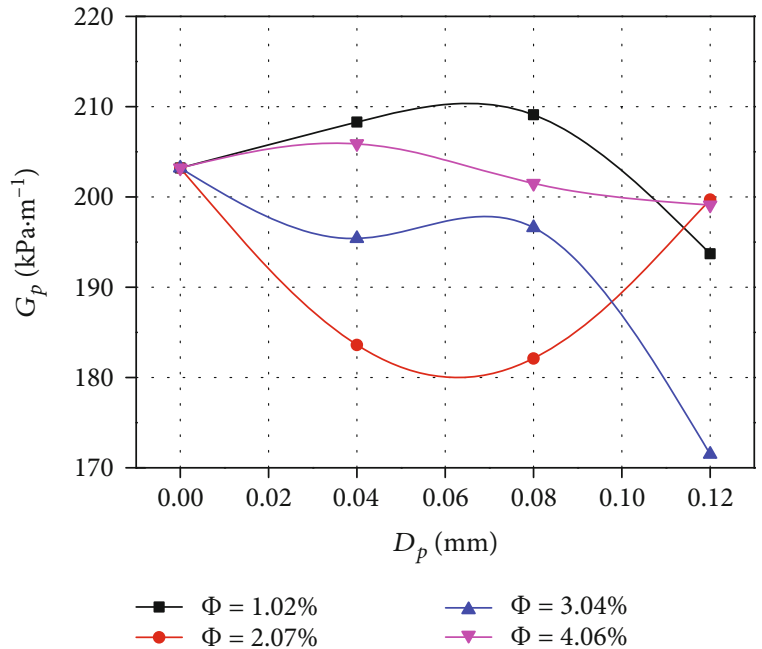

(b) $n=400 \mathrm{r} / \mathrm{min}$

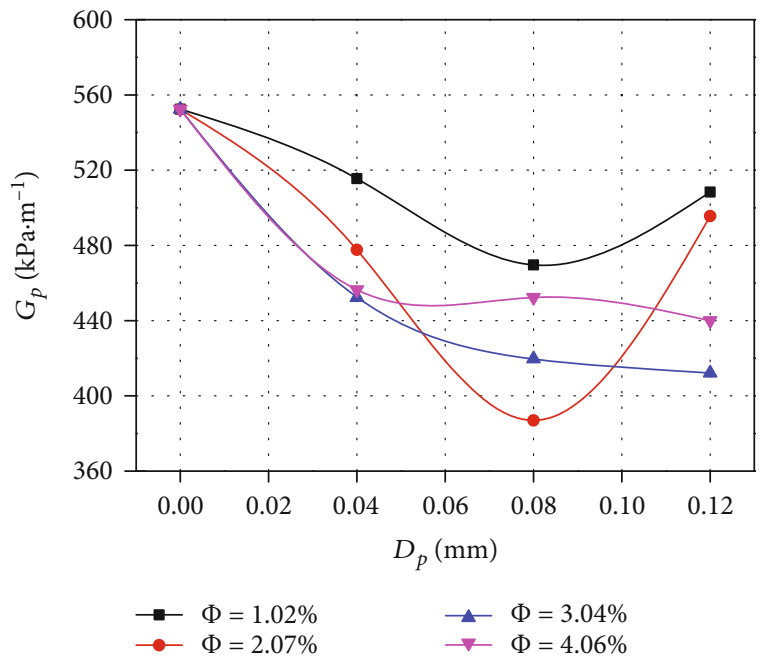

(d) $n=800 \mathrm{r} / \mathrm{min}$

Figure 8: $G_{\mathrm{p}}-D_{\mathrm{p}}$ curves.

$$
B^{\mathrm{p}}=\frac{1-\Phi}{\Phi} B^{\mathrm{w}}
$$

According to the density of sand, the quality of sand could be calculated as follows:

$$
m^{\mathrm{p}}=\rho^{\mathrm{p}} B^{p}
$$

By substituting equation (29) into equation (30), equation (31) could be obtained.

$$
m^{\mathrm{p}}=\frac{1-\Phi}{\Phi} \rho^{\mathrm{p}} B^{\mathrm{w}}
$$

(ii) The second step was to turn on the motor to drive the stirring impeller to make sand particles mix in the water. After a certain period of stirring, the screw pump was started to extract watersediment mixtures. The sand concentration (volume fraction) $\tilde{\Phi}$ was measured. If there was a big difference between $\tilde{\Phi}$ and $\Phi$, a hand pump was used to lift the container. At this point, the sand concentration would be measured again. After the relative error between $\tilde{\Phi}$ and $\Phi$ was no more than $5 \%$, the handle of the reversing valve of the hand pump was placed at the neutral position to stop the movement of the double-acting hydraulic cylinder

(iii) The screw pump was connected to the permeameter by a hose to form a penetration channel. The permeameter was connected with the stirring pool to form a backflow channel

(iv) VVVF (Variable Voltage and Variable Frequency) was used to adjust the screw pump rotation speed 
to $n_{1}=200(\mathrm{r} / \mathrm{min})$. The real-time flow and pressure displayed by the paperless recorder were observed. After the flow and pressure became stable, the flow $Q_{1}$ and pressure in pipeline $p_{1}^{\prime}$ were recorded

(v) The screw pump rotational speeds were adjusted to $n_{2}=400(\mathrm{r} / \mathrm{min}), n_{3}=600(\mathrm{r} / \mathrm{min})$, and $n_{4}=800(\mathrm{r} /$ min), and the corresponding flows $Q_{i}(i=2,3,4)$ and pressures $P_{i}^{\prime}(i=2,3,4)$ were recorded

(vi) The screw pump was closed and $\Phi$ was changed. Steps (i) to (v) were repeated

(vii) The screw pump was closed and $D_{\mathrm{p}}$ was changed. Steps (i) to (vi) were repeated

(viii) According to above steps, the water-sediment seepage tests were completed for three groups of sediments with different particle sizes and five groups of sediments with different volume fractions. The penetration test was carried out with the fracture width of $0.8 \mathrm{~mm}, D_{\mathrm{p}}$ of 0.02 $0.06 \mathrm{~mm}$, and $\Phi$ of $4.06 \%$. Figure 5 shows the pressure-time curve and flow-time curve. It could be seen that when the screw pump rotational speed became stable, the volume flow of the watersediment mixture changed slightly, and the average value was relatively stable. This showed that the fracture resistance had little effect on screw pump displacement

\section{Pressure Gradient Change Characteristics of Water-Sediment Two-Phase Seepage in Coarse Fractures}

3.1. Nonlinear Characteristics of Water-Sediment Two-Phase Seepage. Figure 6 shows the change curves of absolute values of pressure gradient $G_{p}$ of water-sediment mixtures with the flow rate $V$ in coarse fractures under different sand particle sizes $D_{\mathrm{p}}$ and sand concentrations $\Phi$. As $V$ increased, $G_{\mathrm{p}}$ increased gradually. A remarkable nonlinear relationship existed between $G_{\mathrm{p}}$ and $V$, proving that the watersediment two-phase seepage in fracture specimens belonged to the typical non-Darcy flow.

3.2. Variation Laws of Pressure Gradient with the Sand Volume Fraction. Figure 7 shows change curves of the pressure gradient $G_{\mathrm{p}}$ with the sand volume fraction $\Phi$ under various screw pump rotational speeds $n$. When $n$ were $200 \mathrm{r} /$ min and $400 \mathrm{r} / \mathrm{min}$, change characteristics of curves were similar. When $n$ were $600 \mathrm{r} / \mathrm{min}$ and $800 \mathrm{r} / \mathrm{min}$, the characteristics of curves varied a lot.

In Figures 7(a) and 7(b), under low rotational speeds and three kinds of sand particle sizes, the absolute value of $G_{\mathrm{p}}$ firstly increased, then decreased, and increased again with the change of sand particle volume fraction $\Phi$. When $D_{\mathrm{p}}=0.02 \sim 0.06 \mathrm{~mm}$ and $D_{\mathrm{p}}=0.06 \sim 0.10 \mathrm{~mm}$, monotone intervals of $G_{\mathrm{p}}-\Phi$ curves were consistent. When $D_{\mathrm{p}}=$
TABLE 1: Parameters involved in water-sediment seepage in rock fractures under various conditions.

\begin{tabular}{lccc}
\hline$D_{\mathrm{p}}(\mathrm{mm})$ & $\Phi(\%)$ & $I_{\mathrm{e}}\left(\mathrm{m}^{n+2} \cdot \mathrm{s}^{2-n} \cdot \mathrm{kg}^{-1}\right)$ & $\beta\left(\mathrm{m}^{-1}\right)$ \\
\hline 0 & 0 & $5.06 \times 10^{-7}$ & $6.87 E+05$ \\
& $1.02 \%$ & $1.46 E-08$ & $5.72 E+05$ \\
$0.02-0.06$ & $2.07 \%$ & $1.91 E-08$ & $5.41 E+05$ \\
& $3.04 \%$ & $7.17 E-09$ & $4.11 E+05$ \\
& $4.06 \%$ & $6.40 E-09$ & $3.98 E+05$ \\
& $1.02 \%$ & $7.59 E-09$ & $4.39 E+05$ \\
$0.06-0.10$ & $2.07 \%$ & $6.03 E-09$ & $3.01 E+05$ \\
& $3.04 \%$ & $5.91 E-09$ & $3.35 E+05$ \\
& $4.06 \%$ & $6.67 E-09$ & $4.00 E+05$ \\
& $1.02 \%$ & $2.68 E-08$ & $5.96 E+05$ \\
& $2.07 \%$ & $1.25 E-08$ & $5.33 E+05$ \\
$0.10-0.14$ & $3.04 \%$ & $1.04 E-08$ & $4.01 E+05$ \\
& $4.06 \%$ & $6.82 E-09$ & $3.88 E+05$ \\
\hline
\end{tabular}

$0.10 \sim 0.14 \mathrm{~mm}$, monotone intervals changed significantly, presenting that the whole of the curve shifted to the right. The comparison of two groups of curves indicated that when $n=200 \mathrm{r} / \mathrm{min}$, three groups of $G_{\mathrm{p}}-\Phi$ curves showed an overall upward trend, while with $n=400 \mathrm{r} / \mathrm{min}$, they showed horizontal fluctuations.

In Figures $7(\mathrm{c})$ and $7(\mathrm{~d})$, under high rotational speeds and three kinds of sand particle sizes, the change of $G_{p}$ with $\Phi$ firstly decreased and then increased, showing an overall downward trend.

Comparisons of each group of curves indicated that the curves of pressure gradient absolute values and sand particle volume fraction had multiple monotonicity. When the flow velocity was low, sand movement increased the pressure loss of the water-sediment flow in fractures. As the flow velocity increased, the pressure loss also decreased.

3.3. Variation Laws of Pressure Gradient with the Sand Particle Size. In the water-sediment mixture, the sand particle size could affect the pressure gradient. Figure 8 gives variation laws of $G_{\mathrm{p}}$ with $D_{\mathrm{p}}$ under various conditions.

In Figure $8(\mathrm{a})$, with $n$ of $200 \mathrm{r} / \mathrm{min}$ and various $\Phi$, the absolute values of $G_{p}$ first increased and then decrease with the increase in $D_{\mathrm{p}}$, showing an overall upward trend with different positions of extreme points of $G_{\mathrm{p}}$. Compared with the two groups of curves with $\Phi$ values of $1.02 \%$ and $2.07 \%$, the maximum values of curves with $\Phi$ of $3.04 \%$ and $4.06 \%$ shifted to the right. When $n$ increased to $400 \mathrm{r} / \mathrm{min}$ in Figure 8(b), $G_{\mathrm{p}}-D_{\mathrm{p}}$ curves had obvious differences under four kinds of $\Phi$, showing horizontal fluctuations on the whole.

As $n$ increased to $600 \mathrm{r} / \mathrm{min}$ in Figure 8(c), the variation trends of two kinds of curves with $\Phi$ of $1.02 \%$ and $2.07 \%$ were relatively consistent. $G_{\mathrm{p}}$ first decreased and then 


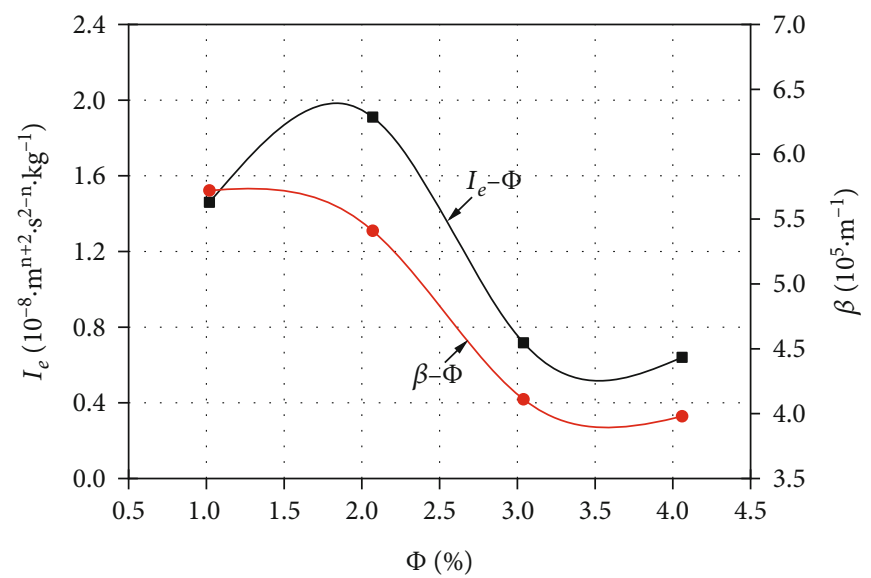

(a) $D_{\mathrm{p}}=0.02 \sim 0.06 \mathrm{~mm}$

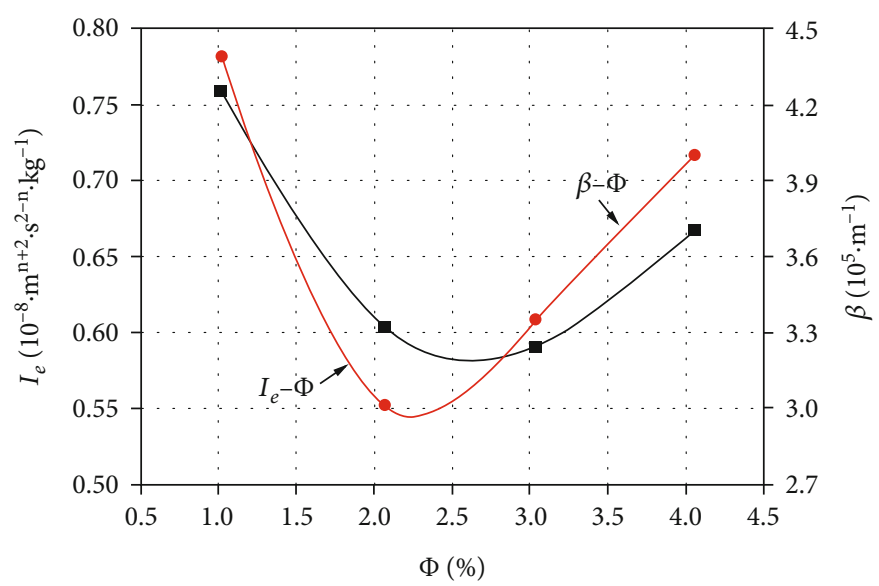

(b) $D_{\mathrm{p}}=0.06 \sim 0.10 \mathrm{~mm}$

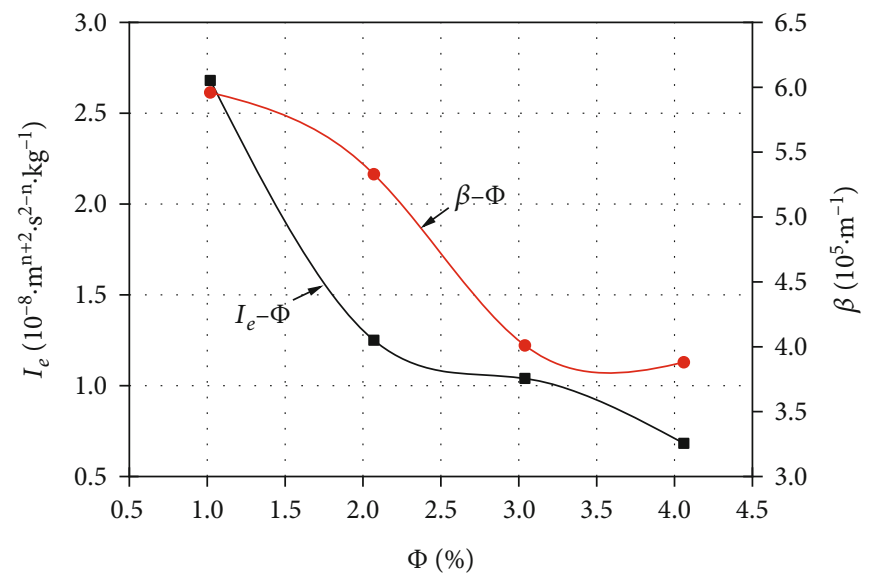

(c) $D_{\mathrm{p}}=0.10 \sim 0.14 \mathrm{~mm}$

FIGURE 9: Variation curves of seepage parameters with the sand volume fraction.

increased with the increase in $D_{\mathrm{p}}$. When $\Phi$ were $3.04 \%$ and $4.06 \%, G_{\mathrm{p}}$ decreased with the increase in $D_{\mathrm{p}}$. When $n=800$ $\mathrm{r} / \mathrm{min}$, the change characteristics of the lower curve were basically the same with those when $n=600 \mathrm{r} / \mathrm{min}$. That is, under low $\Phi, G_{\mathrm{p}}$ first decreased and then increased with the increase in $D_{\mathrm{p}}$, while under high $\Phi, G_{\mathrm{p}}$ reduced gradually with the increase in $D_{\mathrm{p}}$.
On the whole, the variation of sand particle size could significantly change the characteristics of pressure gradient. Meanwhile, the changes of the rotational speed of the pump and sand concentration could also affect the pressure gradient. When the flow velocity was low and the particle size was large, the particle movement caused loss of pressure. As the flow velocity increased, the pressure loss became weak gradually. 


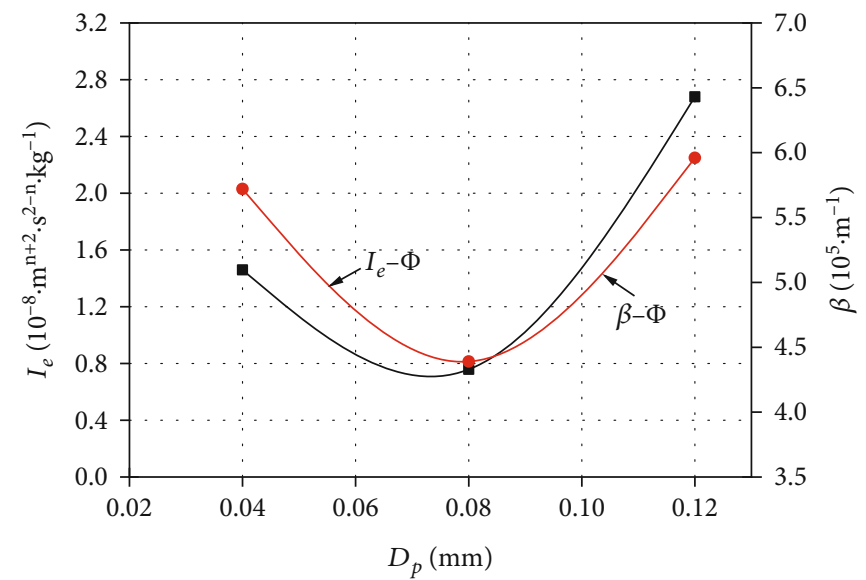

(a) $\Phi=1.02 \%$

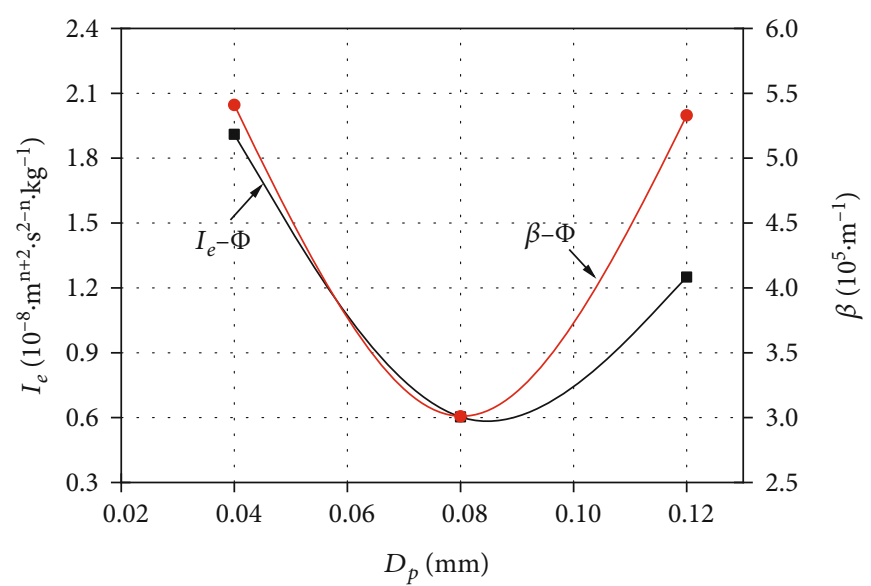

(b) $\Phi=2.07 \%$

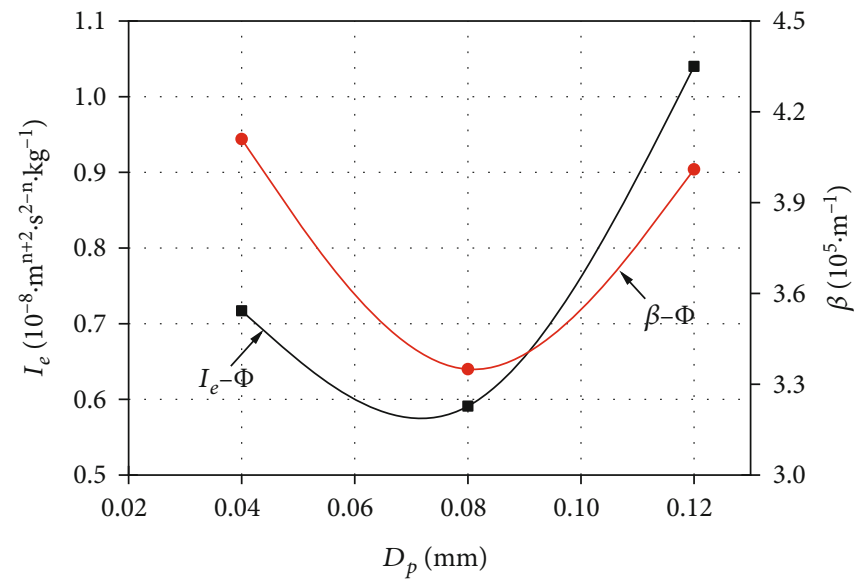

(c) $\Phi=3.04 \%$

Figure 10: Continued. 


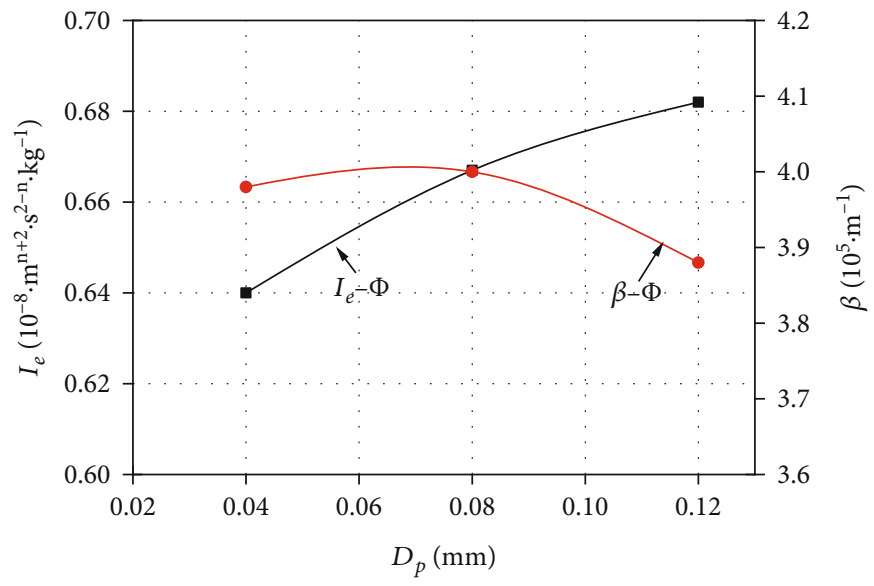

(d) $\Phi=4.06 \%$

Figure 10: Variation laws of $I_{\mathrm{e}}$ and $\beta$-factor with $D_{\mathrm{p}}$.

\section{Change Characteristics of Parameters Involved in the Water-Sediment Two-Phase Seepage in Coarse Fractures}

Based on the experimental results and calculations, the equivalent fluidity $I_{\mathrm{e}}$ and $\beta$-factor of non-Darcy flow were obtained under various particle sizes $D_{\mathrm{p}}$ and sand volume fraction $\Phi$, as shown in Table 1 .

4.1. Variations Laws of Seepage Parameters with Sand Volume Fraction. According to the data in Table 1, variation curves of the equivalent $I_{\mathrm{e}}$ and $\beta$-factor of non-Darcy flow with the sand volume fraction were obtained under three kinds of particle sizes, as shown in Figure 9.

Figure 9 shows that variation laws of $I_{\mathrm{e}}$ and $\beta$-factor of non-Darcy flow with $\Phi$ were basically the same, proving that the two factors could represent the same seepage characteristics. With $D_{\mathrm{p}}$ between 0.02 and $0.06 \mathrm{~mm}$, as $\Phi$ increased, $I_{\mathrm{e}}$ and $\beta$-factor showed an overall decreasing trend. When $\Phi$ increased from $1.02 \%$ to $2.07 \%, I_{\mathrm{e}}$ showed a small increase, while $\beta$-factor was basically unchanged. When $\Phi$ increased from $3.04 \%$ to $4.06 \%, I_{\mathrm{e}}$ and $\beta$-factor were basically unchanged. When $\Phi$ increased from $2.07 \%$ to $3.04 \%$, $I_{\mathrm{e}}$ and $\beta$-factor decreased by over $60 \%$. When $D_{\mathrm{p}}=0.06$ $\sim 0.10 \mathrm{~mm}, I_{\mathrm{e}}$ and $\beta$-factor increased with $\Phi$, showing the trend of first decreasing and then increasing. When $D_{\mathrm{p}}=$ $0.10 \sim 0.14 \mathrm{~mm}, I_{\mathrm{e}}$ and $\beta$-factor decreased rapidly with the increase in $\Phi$.

4.2. Variation Laws of Seepage Parameters with the Sand Particle Size. Based on the experimental results, variation laws of $I_{\mathrm{e}}$ and $\beta$-factor with $D_{\mathrm{p}}$ were obtained, as shown in Figure 10.

Figure 10 indicates that variation laws of $I_{\mathrm{e}}$ and $\beta$-factor with $D_{\mathrm{p}}$ were basically the same. When $\Phi=1.02 \%, 2.07 \%$, and $3.04 \%, I_{\mathrm{e}}$ and $\beta$-factor first decreased and then increased with the increase in $D_{\mathrm{p}}$. When $\Phi=4.06 \%, I_{\mathrm{e}}$ increased with the increase in $D_{\mathrm{p}}$ and the increase became slow gradually, while $\beta$-factor first increased and then decreased and the overall amplitude of variation was not obvious.

4.3. Analysis and Discussions. In seepage mechanics, the equivalent fluidity $I_{\mathrm{e}}$ refers to the ratio of the flow and cross-sectional area. It is used to represent the seepage capacity of the mixtures. The larger the value, the stronger the seepage capacity. $\beta$-factor of non-Darcy flow is used to represent nonlinear characteristics of seepage in fractures. The larger the value, the more obvious the nonlinear characteristics. Compared with the water phase seepage flow, the sand particle size and the sand concentration (volume fraction) are important factors affecting the water-sediment flow in fractures, which has been illustrated in the experiment.

In the fixed mixtures with various sand particle sizes, the higher the sand volume fraction, the narrower the overall permeable channel of the fracture and the lower the permeability of the fracture, resulting in a smaller equivalent fluidity $I_{\mathrm{e}}$. Meanwhile, the narrow permeable channel reduced the nonlinear characteristics of the seepage, macroscopically characterized by the decrease in $\beta$-factor of non-Darcy flow, as shown in Figures 9(a) and 9(c). However, remarkable solid-liquid two-phase seepage characteristics existed when the water-sand mixture passed through the narrow channel, which led to significant nonlinear changes in seepage parameters under certain conditions. As shown in Figure 9(b), when $D_{\mathrm{p}}=0.06 \sim 0.10 \mathrm{~mm}$, the solid-liquid two-phase seepage might cause turbulent flow to occur in the local channel, as the sand volume fraction increased from $2.07 \%$ to $3.04 \%$, causing sudden changes in variation laws of seepage parameters.

When the sand volume fraction was fixed in the watersediment mixture, variations of the sand particle sizes could lead to uncertain nonlinear seepage characteristics in the seepage process. The increase in the particle size firstly narrowed the local permeable channels, weakened the whole seepage capacity in fractures, and lowered the nonlinear seepage characteristics of the medium. As the particle size further increased, the overall migration capacity of the water-sediment mixture increased. The overall impact 
capacity of the mixture on the channel section enhanced. The equivalent fluidity of the sandstones became larger. Meanwhile, local turbulence could be found around the particles, leading to the increase in the equivalent fluidity $I_{\mathrm{e}}$ in the channel of fractures and $\beta$-factor of non-Darcy flow. The processes are shown in Figures 10(a)-10(c). When the volume fraction of the water-sediment mixture reached a certain level, the influences of the particle clusters composed of fine particles and the large-volume particles on the overall seepage characteristics were basically unchanged; that is, the change characteristics of $I_{\mathrm{e}}$ and $\beta$-factor of non-Darcy flow were not obvious, as shown in Figure 10(d).

\section{Main Conclusions}

To further clarify the mechanism of mine water inrush hazards, this paper carried out an experiment to study mechanical characteristics of the water-sediment two-phase seepage in prefabricated coarse fractures. The nonlinear characteristics of the water-sediment seepage in fractures were studied systematically, and the influencing factors were analyzed in detail. The main research conclusions are as follows:

(i) Based on theory of seepage mechanics, the formulas for the principle of the water-sediment two-phase seepage in fractures were deduced. The mechanical model was established. A system was developed to conduct the water-sediment seepage test, and the characterization parameters were determined and analyzed

(ii) Variation laws of the absolute values of the pressure gradients with the seepage velocities were systematically analyzed under various conditions. The nonlinear relationships were clarified. On this basis, it was determined that the water-sediment two-phase seepage test was a typical non-Darcy flow experiment

(iii) The impacts of the sand volume fraction and the sand particle size on the absolute values of the pressure gradients were significant. When the particle size was fixed and the pump rotational speed was slow, the pressure gradient first increased, then decreased, and increased again with the change of the sand volume fraction. When the pump rotational speed was high, the pressure gradient first decreased and then increased. When the sand volume fraction was fixed, the absolute value of pressure gradient changed from first increasing and then decreasing to first decreasing and then increasing, as the speed of the pump changed from high to low. This was related to the pressure loss caused by the sand particle movement

(iv) During the seepage process of the water-sediment seepage in fractures, the change characteristics of equivalent fluidity $I_{\mathrm{e}}$ and $\beta$-factor of non-Darcy flow with the sand volume fraction and the sand particle size were basically the same. When the par- ticle size was fixed, with the higher sand volume fraction, both $I_{\mathrm{e}}$ and $\beta$-factor decreased. When $D_{\mathrm{p}}$ $=0.06 \sim 0.10 \mathrm{~mm}$, they first decreased and then increased. When the sand volume fraction was fixed, they first decreased and then increased with the increase in the sand particle size. When the sand volume fraction was relatively high, they changed slightly

\section{Data Availability}

The data used to support the findings of this study are included within the article.

\section{Conflicts of Interest}

The authors declare that they have no conflict of interest.

\section{Acknowledgments}

This study was funded by the National Natural Science Foundation of China (grant number 52074240).

\section{References}

[1] W. Sun, W. Zhou, and J. Jiao, "Hydrogeological classification and water inrush accidents in China's coal mines," Mine Water and the Environment, vol. 35, no. 2, pp. 214-220, 2016.

[2] S. Dong, H. Wang, X. Guo, and Z. Zhou, "Characteristics of water hazards in China's coal mines: a review," Mine Water and the Environment, vol. 40, no. 2, pp. 325-333, 2021.

[3] J. Chen, J. Zhao, S. Zhang, Y. Zhang, F. Yang, and M. Li, “An experimental and analytical research on the evolution of mining cracks in deep floor rock mass," Pure and Applied Geophysics, vol. 177, no. 11, pp. 5325-5348, 2020.

[4] S. Yin, J. Zhang, and D. Liu, "A study of mine water inrushes by measurements of in situ stress and rock failures," Natural Hazards, vol. 79, no. 3, pp. 1961-1979, 2015.

[5] Y. Qin and J. Lu, "Prediction of coal mine water hazards: a case study from the Huainan coalfield," Arabian Journal of Geosciences, vol. 12, no. 3, p. 83, 2019.

[6] G. Zhang, K. Zhang, L. Wang, and Y. Wu, "Mechanism of water inrush and quicksand movement induced by a borehole and measures for prevention and remediation," Bulletin of Engineering Geology and the Environment, vol. 74, no. 4, pp. 1395-1405, 2015.

[7] W. Yang, L. Jin, and X. Zhang, "Simulation test on mixed water and sand inrush disaster induced by mining under the thin bedrock," Journal of loss prevention in the process industries, vol. 57, pp. 1-6, 2019.

[8] S. Lei, X. Feng, and W. Shidong, "Water-sand mixture inrush through weakly cemented overburden at a shallow depth in the Yili coal mining area," Arabian Journal of Geosciences, vol. 14, no. 12, p. 1103, 2021.

[9] Y. Wang, F. Geng, S. Yang, H. Jing, and B. Meng, "Numerical simulation of particle migration from crushed sandstones during groundwater inrush," Journal of hazardous materials, vol. 362, pp. 327-335, 2019.

[10] F. Du, G. Jiang, and Z. Chen, "A numerical simulation study of the migration law of water-sand two-phase flow in broken rock mass," Geofluids, vol. 2018, 12 pages, 2018. 
[11] J. Wang, Y. Zhang, Z. Qin, S. Song, and P. Lin, "Analysis method of water inrush for tunnels with damaged waterresisting rock mass based on finite element method-smooth particle hydrodynamics coupling," Computers and Geotechnics, vol. 126, article 103725, 2020.

[12] W. Zhong, Y. Xiong, Z. Yuan, and M. Zhang, "DEM simulation of gas-solid flow behaviors in spout-fluid bed," Chemical Engineering Science, vol. 61, no. 5, pp. 1571-1584, 2006.

[13] B. Zhang, Q. He, Z. Lin, and Z. Li, "Experimental study on the flow behaviour of water-sand mixtures in fractured rock specimens," International Journal of Mining Science and Technology, vol. 31, no. 3, pp. 377-385, 2021.

[14] Q. Liu and B. Liu, "Experiment study of the failure mechanism and evolution characteristics of water-sand inrush geo-hazards," Applied Sciences, vol. 10, no. 10, p. 3374, 2020.

[15] Q. Yin, G. Ma, H. Jing et al., "Hydraulic properties of 3D rough-walled fractures during shearing: an experimental study," Journal of Hydrology, vol. 555, pp. 169-184, 2017.

[16] Z. Zhou, J. Zhang, X. Cai, S. Wang, X. Du, and H. Zang, "Permeability experiment of fractured rock with rough surfaces under different stress conditions," Geofluids, vol. 2020, 15 pages, 2020.

[17] J. Xu, H. Pu, J. Chen, and Z. Sha, "Experimental study on sand inrush hazard of water-sand two-phase flow in broken rock mass," Geofluids, vol. 2021, 9 pages, 2021.

[18] Y. Liu and S. Li, "Influence of particle size on non-Darcy seepage of water and sediment in fractured rock," Springerplus, vol. 5, no. 1, p. 2099, 2016.

[19] B. Guo, C. Wang, L. Wang, Y. Chen, and T. Cheng, "A modified cubic law for rough-walled marble fracture by embedding peak density," Advances in Civil Engineering, vol. 2020, 10 pages, 2020.

[20] F. Ye, J.-C. Duan, W.-X. Fu, and X.-Y. Yuan, "Permeability properties of jointed rock with periodic partially filled fractures," Geofluids, vol. 2019, 14 pages, 2019.

[21] T. Xiao, M. Huang, and M. Gao, "Triaxial permeability experimental study on deformation and failure processes of singlefractured rock specimens," Shock and Vibration, vol. 2020, 12 pages, 2020.

[22] Z. Chao, G. Ma, X. Hu, and G. Luo, "Research on anisotropic permeability and porosity of columnar jointed rock masses during cyclic loading and unloading based on physical model experiments," Bulletin of Engineering Geology and the Environment, vol. 79, no. 10, pp. 5433-5454, 2020.

[23] Y. Chen, W. Liang, H. Lian, J. Yang, and V. P. Nguyen, "Experimental study on the effect of fracture geometric characteristics on the permeability in deformable rough-walled fractures," International Journal of Rock Mechanics and Mining Sciences, vol. 98, no. July, pp. 121-140, 2017. 